\title{
Организационно-правовое обеспечение экономической безопасности России: системно-структурный анализ
}

\author{
Л. П. Гончаренко \\ Российский экономическийуниверситет им. Г. В. Плеханова \\ Стремянный пер., д. 36, 117997, Москва, Россия, E-mail: inn.invest@mail.ru \\ С. А. Сыбачин \\ Российский экономическийуниверситет им. Г. В. Плеханова \\ Стремянный пер., д. 36, 117997, Москва, Россия, E-mail: sergeysyb@mail.ru \\ Т. Э. Зульфугарзаде \\ Российский экономическийуниверситет им. Г. В. Плеханова \\ Стремянный пер., д. 36, 117997, Москва, Россия, E-mail: teymurz@yandex.ru
}

\begin{abstract}
Целью исследования является определение основных недостатков современного правового обеспечения экономической безопасности в Российской Федерации и внесение предложения по их нивелированию; выработка инновационных организационно-правовых механизмов стратегического управления в сфере обеспечения экономической безопасности. Достоверность проведенного научного исследования и обоснованность аргументации авторов обеспечиваются применением не только эмпирических, но и теоретических методов познания (описание, анализ, синтез, индукция, дедукция). Помимо общенаучных методов, в работе также использовались специально-юридические методы исследования: формально-юридический, сравнительно-правовой. На основе анализа нормативных правовых актов, регулирующих основные начала экономбезопасности, проведено исследование таких понятий как экономическая безопасность и ее обеспечение, единство экономического пространства, экономический суверенитет России; проведен сравнительно-правовой анализ понятий национальной и государственной безопасности. Выявлены основные недостатки правового обеспечения в исследуемой сфере отношений и внесены предложения по совершенствованию правового обеспечения вышеперечисленных понятий, учитывающие современные тенденции глобализации и цифровизации современной социально-экономической системы. В статье впервые вносятся предложения по комплексному правовому регулированию таких базовых дефиниций, как «единство экономического пространства» и «экономический суверенитет Российской Федерации». Внесены предложения по совершенствованию правового обеспечения противодействия неблагоприятным последствиям гибридных войн, кибертеррористических и иных угроз экономбезопасности нашей страны. Основные положения и выводы статьи могут быть использованы в научной, научно-исследовательской и образовательной деятельности, прежде всего при рассмотрении вопросов правового обеспечения экономической безопасности как составной части безопасности национальной и планетарной.

Ключевые слова: экономическая безопасность; кибербезопасность; стратегическое управление; юриспруденция.
\end{abstract}

\section{Procedural and Legal Support of Economic Security of Russia: System and Structural Analysis}

\author{
L. P. Goncharenko \\ Plekhanov Russian University of Economics \\ per. Stremyannyi, 36, 117997, Moscow, Russia, E-mail: inn.invest@mail.ru \\ S. A. Sybachin \\ Plekhanov Russian University of Economics \\ per. Stremyannyi, 36, 117997, Moscow, Russia, E-mail:sergeysyb@mail.ru \\ T. E. Zulfugarzade \\ Plekhanov Russian University of Economics \\ per. Stremyannyi, 36, 117997, Moscow, Russia, E-mail:teymurz@yandex.ru
}


The aim of the study is to identify the main shortcomings of the modern legal provision of economic security in the Russian $\mathrm{F}$ ederation and make proposals for their leveling; development of innovative procedural and legal mechanisms of strategic management in the field of economic security. The reliability of the scientific research carried out and the validity of the authors' grounding are provided by the employment of both empirical and theoretical methods of cognition (description, analysis, synthesis, induction, deduction). In addition to general scientific methods, specialized techniques for legal sphere were also used in the work: technical legal, comparative legal. On the basis of the analysis of legal regulations determining the basic principles of economic security, there have been studied such concepts as economic security and its promotion, the integrity of economic space, economic sovereignty of Russia, as well as comparative legal analysis of the concepts of national and public security has been carried out. The main shortcomings of legal support in the studied sphere of relations have been revealed and proposals for improving the legal support of the above concepts have been made, taking into account the current trends of globalization and digitalization of the modern socio-economic system. It is the first time an article has made proposals on the complex legal regulation of such basic definitions as "integrity of economic space" and "economic sovereignty of the Russian Federation". Proposals have been made to improve the legal framework for preventing the adverse consequences of hybrid wars, cyber terrorist and other threats to the economic security of our country. The main concepts and conclusions of the article can be used in science, research and education, especially when considering the legal provision of economic security as an integral part of national and world security.

Key words: economic security; cyber security; strategic management; jurisprudence.

В современных условиях глобализации и цифровизации экономики возрастают риски наступления неблагоприятных последствий, связанных в том числе с киберугрозами [Сенчагов 2016: 201]. Проведенный анализ действующих нормативных правовых актов РФ позволил выявить основные недостатки нормативно-правового обеспечения экономической безопасности в нашей стране и внести следующие предложения по ихустранению.

1. Понятие экономической безопасности. С юридической точки зрения экономбезопасность, что прямо определено подп. 1 п. 7 ст. I СэБ РФ, представляет собой, прежде всего, состояние защищенности национальной (т. е. российской, что непосредственно следует из названия исследуемого документа и прямо конкретизировано в завершающих двух словах рассматриваемой дефиниции) экономики от внешних и внутренних (внутригосударственных) угроз, при котором обеспечиваются экономический суверенитет (как составная и неотъемлемая часть суверенитета РФ) страныі (в данном контексте термин «страна» указан как синоним термина «государство»), единство ее экономического пространства (далее также - ЕЭП) и, наконец, условия для реализации стратегических национальных приоритетов РФіі. Таким образом, учитывая, что в соответствии со Стратегий экономической безопасности РФ (юридически корректно гармонизированной с актуальными конституционно-правовыми доктринальными подходами), по общей направленности стратегического планирования, основной приоритет направлен теперь не только на социально-экономическую безопасность, но также и на государственно-военно-оборонно-экономическую безопасность нашей страны, представляется возможным сделать вывод о том, что экономбезопасность России является одним из основополагающих компонентов безопасности национальной, государственной [Сенчагов 2016: 7], в том числе и не в последнюю очередь, военной (оборонной и оборонно-промышленной).

2. Понятие единства экономического пространства. В настоящее время в России полностью отсутствует легитимированная дефиниция такого важного понятия, как «единство экономического пространства», принципы которого закреплены в ч. 1 ст. 8 Конституции РФіv. В системе надлежащего правового обеспечения экономбезопасности нашей страны данное понятие следует признать одним из базовых. Профессор Ш. Г. Сеидов предложил следующую заслуживающую внимания дефиницию понятия «единое экономическое пространство»: «принцип экономической основы конституционного строя, предполагающий общее правовое регулирование экономических отношений, установление единых правил поведения, инфраструктурных гарантий в экономической сфере и обеспечение экономической безопасности» [Сеидов, Зернов 2017: 20]. Указанной дефиницией целесообразно дополнить п. 7 ст. І СЭБ РФ.

3. Особенности правового статуса экономического суверенитета России. Вопрос об использовании в тексте СэБ РФ термина «гражданин» [Минникес 2007: 8] является весьма важным (целесообразно отметить, что в СНБ РФ указанный термин использован одиннадцать раз). В соответствии с положениями Российской Конституции носителем суверенитета в РФ является исключительно «многонациональный народ» (ч. 1 ст. 3), то есть, фактически, его легитимный представитель - сама странаvі (государство), Российская Федерация (ч. 1 ст. 4) в лице Президента РФ, к обязанностям которого отнесена охрана суверенитета (ч. 2 ст. 80). Наряду с термином «народ» в конституирующем политико-правовом акте нашей страны, имеющем высшую юридическую силу, употребляется термин «гражданин», по смыслу замещающий первый термин (см., напр., ч. 2 ст. 6, ч. 2 ст. 7, ч. 2 ст. 15 и др. Конституции РФ). В ука занной связи дополнительно отметим, что в нормативных правовых актах о безопасности вместо конституционного термина «народ", как правило, применяются термины «гражданин», «граждане» [Минникес 2007: 8]. Так, в частности, термин «гражданин» употребляется в Ф3 о безопасности vii (см. статьи 2, 4, 7 и др.), в ч. 4 ст. 4 которого граждане, наравне с общественными объединениями, относятся к участникам реализации госполитики в области обеспечения безопасности (а следовательно, в соответствии с правилами формальной логики, и экономбезопасности). В указанной связи отметим, что в современной правовой доктрине под термином «гражданин» принято понимать граждан РФ (лиц, обладающих гражданством России), иностранных граждан (граждан или подданных иностранных государств) и, наконец, лиц, не имеющих гражданства или подданства ни одного государства мира, т. е. так называемых «лиц без гражданства» (не приобретших или лишенных гражданства или подданства) viii. При этом термин «гражданин» распространяется на иностранцев и лиц без гражданства при условии их нахождения на территории РФ. На граждан РФ данный термин распространяется независимо от места их нахождения - на территории России или за рубежом. Таким образом, объективно возможно признать термины "народ" [Сухарева 2009: 858] и «граждане» равнозначными (тождественными) и внести соответствующие дополнения в текст п. 7 ст. І СЭБ РФ и иные нормативные правовые акты в сфере обороны и безопасности (в том числе в упомянутый выше Фз о безопасности, а также федеральные законы об обороне ${ }^{\mathrm{ix}}$, о безопасности КИИ РФ, о госохранехі, о безопасности объектов ТЭК ${ }^{\mathrm{xii}}$, о безопасности ГТС и др.).

Также, как отмечено выше, в СЭБ РФ термин «страна» применяется в значении термина «государство», таким образом, указанные термины следует считать тождественными. Полагаем, что во избежание разночтений указанную терминологическую тождественность целесообразно закрепить в п. 7 ст. І СЭБ РФ, а также в иных нормативных правовых актах в сфере обороны и безопасности.

Безусловно, конституционно-правовое обеспечение и регулирование отечественной системы экономбезопасности носит комплексный и многоаспектный (практически, мультикомплексный) характер, что в свою очередь предполагает создание мультикомплексной системы правовых, административно-организационных и экономических механизмов, способных обеспечить гарантии прав граждан и других субъектов экономической деятельности на защитучастной собственности [Jamison 2018], экономиче скую свободу и беспрепятственное осуществление легитимной предпринимательской и иной экономической деятельности. Это требует от государства создания благоприятных үсловий для зашиты интересов отечественных производителей, развития цивилизованных 
рыночных отношений, повышения инвестиционной активности, а также для устранения правонарушений в экономической сфере. В указанной связи также заслуживает внимания мнение Ш. Б. Магомедова о необходимости «законодательного закрепления (по аналогии с США) сущности и форм наступательных мер в целях надлежащего применения экономического механизма» [Магомедов 2019: 14] обеспечения экономбезопасности России.

4. Понятия нацбезопасности и госбезопасности. В тексте СЭБ РФ выявлен диссонанс в применении терминов «государственная безопасность» и «национальная безопасность». Соглашаясь с мнением российского правоведа Г. В. Федулова [Федулов 2019: 49], считаем целесообразным рассматривать феномен национальной безопасности тождественным понятиям госбезопасности и безопасности. Следовательно, термины «безопасность», «государственная безопасность» и «национальная безопасность», в целях Сэв РФ, следует считать равноценными, что, по аналогии с терминами «государство» и «страна», также должно найти свое закрепление в п. 7 ст. І СЭБ РФ и п. 6 ст. І СНБ РФ, а также в иных нормативных правовых актах в сфере обороны и безопасности.

5. Понятие обеспечения экономической безопасности ${ }^{x v}$ (далее - ОЭБ). Согласно подп. 7 п. 7 ст. І СЭБ РФ, обеспечение экономбезопасности представляет собой реализацию субъектами ОЭБ комплекса мер, направленных на противодействие вызовам и угрозам экономической безопасности и защиту национальных интересов РФ в экономической сфере. В исследуемой норме в перечне субъектов ОЭБ наряду с органами государственной власти и ОМСуказывается Банк России. В действительности Центробанк РФ не входит в структуру органов исполнительной власти РФ. При этом в норме подп. 7 п. 7 ст. І СэБ РФ по каким-то причинам отсутствуют Совбез России, Прокуратура России, Следственный комитет России и Счетная палата РФ, также не входящие в систему органов исполнительн ой власти нашей страны (таким образом, таковые к «госорганам» относится могут опосредовано).

Банк России представляет собой мегарегулятор финансового рынка нашей страны, его имущество, включая уставный капитал, является федеральной собственностьюхvі (тем более что с 2012 года он имеет печать с Государственным Гербом РФ, а с 2017 года Центральный Банк РФ в обязательном порядке наносит на билеты и монеты достоинством в один российский рубль и более не логотип Банка России, а Государственный герб России). Следовательно, наряду с перечисленными выше органами, он должен быть включен в состав госорганов (что не является вполне правильным), либо в подп. 7 п. 7 ст. І СЭБ РФ все указанные выше органы должны быть перечислены как отдельные органы российского государства, например, после слов: «органами местного самоуправления и...».

Помимо этого важно отметить, что в СЭБ РФ в рассматриваемом нами подп. 7 п. 7 ст. I не используются термины «специальные экономические меры» и «принудительные меры», регламентированные ФЗ о СЭМхvіi. СЭБ РФ в подп. 33 ст. V только предусматривает наличие «специальных и иных мер», что явно недостаточно, учитывая наличие ФЗ о СЭМ, который был принят более чем за десять лет до СЭБ РФ. В данной связи полагаем целесообразным дополнить подп. 33 ст. V СЭБ РФ, после слов «военных, специальных...» словами «..., в том числе специальных экономических, принудительных...» (далее - по текстууказанной нормы).

В современный период, характеризуемый цифровизацией социально-экономической сферы, возникают дополнительные риски для имущества собственников и обладателей неимущественных прав, прежде всего интеллектуальных [Войниканис 2013: 14]. Особенную опасность для граждан и субъектов экономической деятельности представляют удаленные воздействия негативного, нередко криминального характера, что помимо цифровизации [Родионова 2019: 96] обусловлено факторами трансграничности и достаточной открытости большей части носителей титульных прав. Это дает злоумышленникам возможность осуществления противоправных действий в отношении не только конкретных субъектов правоотношений, но и национальной экономической инфраструктуры России в целом. В итоге это неблагоприятным образом влияет на состояние военно-политической безопасности нашей страны [Минаков 2019: 20], приводит к развитию так называемых гибридных войн, направленных не только на нелегитимное перераспределение собственности, но и на рост коррупционных правонарушений, оказание давления на политическое руководство государства.

6. Заключение. На основании вышеизложенного, учитывая положения утратившей с 12.02.2019 силу программы ЦЭ РФхvіiі, полагаем целесообразным дополнить подп. 5 п. 18 ст. ІІІ СЭБ РФ после слов «в том числе технологий цифровой экономики...» следующими слов ами: «интеллектуального капитала, больших данных; нейротехнологий и искусственного интеллекта; системы распределенного реестра; квантовых технологий; новых производственных технологий; промышленного интернета [Гуляев 2018: 29-37]; компонентов робототехники и сенсорики; технологий беспроводной связи; технологий виртуальной и дополненной реальности». Также предлагаем включить в текст статьи следующий раздел: «К основным направлениям обеспечения экономбезопасности в сфере цифровой экономики (в современных условиях развития экономики) относятся: (1) инновационное развитие отрасли наноэлектроники, информационнокоммуникационных технологий [Frisby 2019] (ИКТ, инфотехнологий), а также электронной и иной наукоемкой промышленности в целом, постоянное увеличение доли продукции наукоемких отраслей в валовом внутреннем продукте, в структуре экспорта (экспортных поставок) РФ; (2) целенаправленное преодоление зависимости отечественной промышленности (в допустимом объеме), прежде всего ее наукоемких областей, от зарубежных Икт и средств обеспечения безопасности (экономбезопасности) в целом и инфобезопасности (кибербезопасности), с учетом того факта, что только в прошедшем, 2018 году, в РФ «было зафиксировано около 4,3 млрд кибератак» [Федулов 2019: 23], в том числе за счет планирования, создания, развития и широкого внедрения отечественных разработок и разработок, осуществляемых в рамках взаимовыгодных партнерских отношений государствами -участниками СГ, ЕАЭС, БРИКС и ШОС, а также производства высокотехнологичной безопасной продукции и оказания услуг с аналогичными характеристиками на их основе; (3) повышение конкурентоспособности на внутреннем и международном рынках отечественных субъектов экономической деятельности (экономических субъектов), осуществляющих деятельность в отрасли ИкТ и иной наукоемкой промышленности, разработку, производство и эксплуатацию средств обеспечения кибербезопасности [Lieberman 2010 - 2018] (что является неотъемлемой частью нацбезопасности в целом и экономбезопасности в том числе), оказывающих услуги в указанной области, в том числе за счет создания благоприятных условий для осуществления деятельности на территории РФ; (4) развитие (дальнейшее развитие и совершенствование) отечественной стабильной конкурентоспособной высокотехнологичной электронной элементной (компонентной) и производственной базы, а также технологий производства электронных компонентов (в том числе наномасштаба), обеспечение (с учетом перспектив развития) постоянно нарастающих потребностей внутреннего рынка в высокотехнологичной электронной элементной продукции и выхода таковой продукции на мировой рынок».

На сегодняшний день одним из важнейших аспектов обеспечения системы анализа и мониторинга угроз, рисков и уязвимостей («узких мест» [Селиванов 2018: 3 - 11]) является формирование комплекса моделей, предназначенного для «аутентичного описания объекта мониторинга (российской экономики)» [Селиванов 2019: 3]. С учетом данного факта для обеспечения эффективности и надлежащего проведения мониторинга и оценки ЭБРФ (подп. «б» п. 2 указа Президента РФ от 13.05.2017 № 208) представляется важным дополнить п. 31 ст. IV СЭБ РФ, после слова «самоуправления», следующим словами: «включающими следующие модели: причинноследственных, структурно-функциональных и иных связей и взаимодействий; состава элементной базы объекта и анализа состояний; динамики состояний объекта, включая модели процесса, в том числе процесса развития [Федулов 2019: 287]; ориентированные на 
выявление угроз взаимосвязям, взаимодействиям, процессам, функциям, инфраструктурам материальной и информационной деятельности».

В указанной связи, а также в целях информационно-аналитического обеспечения ЭБ-мониторинга и оценки, необходимо поддержать предложения [Селиванов 2018: 89-95] об обязательной разработке следующих основных структурно-функциональных моделей: модели общественно-экономического развития общества; цивилизационной (национальной и международной) модели и мультиагентной модели на основе блокчейн-технологий [Носов 2016].

Данная статья подготовлена в рамках выполнения проектной части государственного задания по заказу Министерства науки и высшего образования Российской Федерации на тему «Развитие методологических основ и организационно-экономического механизма стратегического управления экономической безопасностью России» (Задание №26.3913.2017/4.6).

\section{Литература}

1. Dole, C.L., Shelkey, D.G. Delaware Blockchain Law Goes into Effect. National Law Review. 2017.11 August. URL: https://www.natlawreview.com/article/delaware-blockchain-law-goes-effect/

2. Frisby, $D$. In proof we trust. Blockchain technology will revolutionise far more than money: it will change your life. Here's how it actually works. Guardian News. URL: https://www.theguardian.com/profile/dominic-frisby/

3. Jamison, M. What does economics say about updating the Communications Act? American Enterprise Institute. 2018. URL: https://www.aei.org/publication/what-does-economics-say-about-updating-the-communications-act/

4. Joseph S. Nye, Jr. How Will New Cybersecurity Norms Develop? Project Syndicate. Mar 8, 2018. URL: https://www.projectsyndicate.org/commentary/origin-of-new-cybersecurity-norms-by-joseph-s--nye-2018-03

5. Lieberman, E. States Are Pushing Their Own Versions Of Net Neutrality Rules While Congress Stalls On Ending Bureaucratic Back-AndForth. The Daily Caller. 2010 - 2018. URL: http://dailycaller.com/2018/03/17/states-pushing-own-versions-of-net-neutrality-rules/

6. Rappaport, M. The Advantages of Soft Regulation. Law \& Liberty. 2019. May 10. URL: https://www.lawliberty.org/2019/05/10/theadvantages-of-soft-regulation/

7. Большой юридический словарь / под ред. А. Я. Сухарева; Волосов М. Е., Додонов В. Н., Капинус Н. И. М., 2009.

8. Войниканис Е.А. Право интеллектуальной собственности в цифровую эпоху: парадигма баланса и гибкости. М., 2013.

9. Гуляев К.С. Право человека на Интернет, права в Интернете и при использовании интернет-вещей: новые тенденции / Прецеденты Европейского суда по правамчеловека. 2018. - № 1. - С. 29-37.

10. Магомедов Ш.Б. К вопросу о конституционном содержании обеспечения экономической безопасности в Российской Федерации / Конституционное и муниципальное право. 2019. - № 1. - С. 10-15.

11. Минаков А.В. Обеспечение экономической безопасности России в условиях развития цифровой экономики / Экономика и бизнес: теория и практика. 2019. - № 3-2. - С. 19-22.

12. Минникес И. Элементы индивидуального правового регулирования в гражданском процессуальном праве / Арбитражный и гражданский процесс. 2007. - № 11. - С. 4-8.

13. Нагродская В.Б. Новые технологии (блокчейн / искусственный интеллект) на службе права: научно-методическое пособие / под ред. Л.А. Новоселовой. М., 2019.

14. Носов Н. Перспективы блокчейн в России: PCWeek. URL: https://www.pcweek.ru/idea/article/detail.php?ID=182389/

15. Родионова М.A. Экономические возможности и угрозы развития блокчейн-технологий: магистерская диссертация по направлению подготовки: 38.04.01 - Экономика. Томск, 2019.

16. Савельев А.И. Электронная коммерция в России и за рубежом: правовое регулирование. 2-е изд. М., 2016.

17. Сеидов Ш.Г., Зернов И.В. Теоретические и правовые основы функционирования конституционного принципа единства экономического пространства / Современное право. 2017. - № 4. - С. 19-23.

18. Селиванов А.И. Методологические основания разработки комплекса моделей анализа угроз экономической безопасности Российской Федерации / Микроэкономика. 2018. - № 5. - С. 89-95.

19. Селиванов А.И. Потенциал модели общественно-экономической формации в комплексе анализа угроз экономической безопасности Российской Федерации / Безопасность бизнеса. 2019. - № 2. - С. 3-10.

20. Селиванов А.И., Трошин Д.В. Категория «уязвимость» в понятийном ряду теории и практики обеспечения безопасности / Безопасность бизнеса. 2018. - № 3. - С. 3-11.

21. Сенчагов В.К. Экономическая безопасность России. Общий курс: учебник / под ред. В.К. Сенчагова - 3-е изд., перераб. и доп. M., 2016.

22. Федулов Г.В. Безопасность как нематериальное благо субъектов гражданского права / Экономика. Право. Общество. 2019. № 1. - C. 48-55.

23. Федулов Г.В. Особенности взаимодействия представителей юридических и экономических специальностей в современных условиях глобализации / Гуманитарное образование в экономическом вузе : материалы VII Международной научно-практической очнозаочной конференции. 1-28 ноября 2018 г. - М., 2019. -С. 285-290.

24. Федулов Г.В. Особенности гражданско-правового обеспечения кибербезопасности образовательных организаций / Экономика. Право. Общество. 2019. - № 2. - С. 22-28.

25. Филатов С. Не «кибервойны» являются сутью нынешнего глобального «выяснения отношений». Международная жизнь. 07.12.2016. URL: https://interaffairs.ru/news/printable/16529

\section{References}

1. Bol'shoj yuridicheskij slovar' / pod red. A. YA. Suhareva; Volosov M. E., Dodonov V. N., Kapinus N. I. M., 2009 (in Russian).

2. Dole, C.L., Shelkey, D.G. Delaware Blockchain Law Goes into Effect. National Law Review. 2017. Available from: https://www.natlawreview.com/article/delaware-blockchain-law-goes-effect/

3. Fedulov G.V. Bezopasnost' kak nematerial'noe blago sub"ektov grazhdanskogo prava / Ekonomika. Pravo. Obshchestvo. 2019. № 1 (in Russian). 
4. Fedulov G.V. Osobennosti grazhdansko-pravovogo obespecheniya kiberbezopasnosti obrazovatel'nyh organizacij / Ekonomika. Pravo. Obshchestvo. 2019. № 2 (in Russian).

5. Fedulov G.V. Osobennosti vzaimodejstviya predstavitelej yuridicheskih i ekonomicheskih special'nostej v sovremennyh usloviyah globalizacii / Gumanitarnoe obrazovanie v ekonomicheskom vuze : materialy VII Mezhdunarodnoj nauchno-prakticheskoj ochno-zaochnoj konferencii. 1-28 noyabrya 2018 g. - M., 2019 (in Russian).

6. Filatov S. Ne «kibervojny» yavlyayutsya sut'yu nyneshnego global'nogo "vyyasneniya otnoshenij». Mezhdunarodnaya zhizn'. 07.12.2016. Available from: https://interaffairs.ru/news/printable/16529 (in Russian).

7. Frisby, D. In proof we trust. Blockchain technology will revolutionise far more than money: it will change your life. Here's how it actually works. Guardian News. Available from: https://www.theguardian.com/profile/dominic-frisby/

8. Gulyaev K.S. Pravo cheloveka na Internet, prava v Internete i pri ispol'zovanii internet-veshchej: novye tendencii / Precedenty Evropejskogo suda po pravam cheloveka. 2018. - № 1, 29-37 (in Russian).

9. Jamison, M. What does economics say about updating the Communications Act? American Enterprise Institute. 2018. Available from: https://www.aei.org/publication/what-does-economics-say-about-updating-the-communications-act/

10. Joseph S. Nye, Jr. How Will New Cybersecurity Norms Develop? Project Syndicate. Mar 8, 2018. Available from: https://www.proj ectsyndicate.org/commentary/origin-of-new-cybersecurity-norms-by-joseph-s--nye-2018-03

11. Lieberman, E. States Are Pushing Their Own Versions Of Net Neutrality Rules While Congress Stalls On Ending Bureaucratic Back-AndForth. The Daily Caller. 2010 - 2018. Available from: http://dailycaller.com/2018/03/17/states-pushing-own-versions-of-net-neutrality-rules/

12. Magomedov SH.B. K voprosu o konstitucionnom soderzhanii obespecheniya ekonomicheskoj bezopasnosti v Rossijskoj Federacii / Konstitucionnoe i municipal'noe pravo. 2019. - № 1, 10-15 (in Russian).

13. Minakov A.V. Obespechenie ekonomicheskoj bezopasnosti Rossii v usloviyah razvitiya cifrovoj ekonomiki / Ekonomika i biznes: teoriya i praktika. 2019. - № 3-2, 19-22 (in Russian).

14. Minnikes I. Elementy individual'nogo pravovogo regulirovaniya v grazhdanskom processual'nom prave / Arbitrazhnyj i grazhdanskij process. 2007. - № 11, 4-8 (in Russian).

15. Nagrodskaya V.B. Novye tekhnologii (blokchejn / iskusstvennyj intellekt) na sluzhbe prava: nauchno-metodicheskoe posobie / pod red. L.A. Novoselovoj. M., 2019 (in Russian).

16. Nosov N. Perspektivy blokchejn v Rossii: PCWeek. Available from: https://www.pcweek.ru/idea/article/detail.php?ID=182389/ (in Russian).

17. Rappaport, M. The Advantages of Soft Regulation. Law \& Liberty. 2019. May 10. Available from: https://www.lawliberty.org/2019/05/10/the-advantages-of-soft-regulation/

18. Rodionova M.A. Ekonomicheskie vozmozhnosti i ugrozy razvitiya blokchejn-tekhnologij: magisterskaya dissertaciya po napravleniyu podgotovki: 38.04.01 - Ekonomika. Tomsk, 2019 (in Russian).

19. Savel'ev A.I. Elektronnaya kommerciya v Rossii i za rubezhom: pravovoe regulirovanie. 2-e izd. M., 2016 (in Russian).

20. Seidov SH.G., Zernov I.V. Teoreticheskie i pravovye osnovy funkcionirovaniya konstitucionnogo principa edinstva ekonomicheskogo prostranstva / Sovremennoe pravo. 2017. - № 4, 19-23 (in Russian).

21. Selivanov A.I. Metodologicheskie osnovaniya razrabotki kompleksa modelej analiza ugroz ekonomicheskoj bezopasnosti Rossijskoj Federacii / Mikroekonomika. 2018. № 5, 89-95 (in Russian).

22. Selivanov A.I. Potencial modeli obshchestvenno-ekonomicheskoj formacii v komplekse analiza ugroz ekonomicheskoj bezopasnosti Rossijskoj Federacii / Bezopasnost' biznesa. 2019. - № 2, 3-10 (in Russian).

23. Selivanov A.I., Troshin D.V. Kategoriya «uyazvimost'» v ponyatijnom ryadu teorii i praktiki obespecheniya bezopasnosti / Bezopasnost' biznesa. 2018. - № 3, 3-11 (in Russian).

24. Senchagov V.K. Ekonomicheskaya bezopasnost' Rossii. Obshchij kurs: uchebnik / pod red. V.K. Senchagova - 3-e izd., pererab. i dop. - M., 2016 (in Russian).

25. Vojnikanis E.A. Pravo intellektual'noj sobstvennosti v cifrovuyu epohu: paradigma balansa i gibkosti. M., 2013 (in Russian).

\section{Citation:}

Гончаренко, Л.П., Сыбачин, С.А., Зульфугарзаде, Т.Э. Организационно-правовое обеспечение экономической безопасности России: системно-структурный анализ. // Юрислингвистика. - 2019. - 14.- С. 5-10.

Goncharenko, L. P., Sybachin, S. A., Zulfugarzade, T. E. (2019). Procedural and legal support of economic security of Russia: system and structural analysis. Legal Linguistics, 14, 5-10.

(cc) $\mathrm{Br}$ This work is licensed under a Creative Commons Attribution 4.0. License

\footnotetext{
i См.: документ «Стратегия экономической безопасности Российской Федерации на период до 2030 года», утв. указом Президента Российской Федерации от 13.05.2017 № 208 «О Стратегии экономической безопасности Российской Федерации на период до 2030 года» (СЗ РФ. 2017. № 20. Ст. 2902).

ii Экономический суверенитет Российской Федерации определен как объективно существующая независимость государства в проведении внутренней и внешней экономической политики с учетом международных обязательств (см.: подп. 1 п. 7 ст. І СЭБ РФ).

iii Национальные приоритеты определены в п. 31 ст. ІІІ Стратегии национальной безопасности Российской Федерации (далее также - СНБ РФ), утв. указом Президента Российской Федерации от 31.12.2015 № 683 «О Стратегии национальной безопасности Российской Федерации» (СЗ РФ. 2016. № 1 (часть ІІ). Ст. 212). К ним отнесены: оборона страны; государственная и общественная безопасность; повышение качества жизни российских граждан; экономический рост; наука, технологии и образование; здравоохранение; культура; экология живых систем и рациональное природопользование; стратегическая стабильность и равноправное стратегическое партнерство. При этом национальные интересы Российской Федерации в экономической сфере - объективно значимые экономические потребности страны, удовлетворение которых обеспечивает реализацию.
}

iv Конституция Российской Федерации (принята всенародным голосованием 12.12.1993) // С3 РФ. 2014. № 31. Ст. 4398. 
v См.: абзац второй подп. 2.1 п. 2 постановления Конституционного Суда Российской Федерации от 07.06.2000 № 10-П «По делу о проверке конституционности отдельных положений Конституции Республики Алтай и Федерального закона «Об общих принципах организации законодательных (представительных) и исполнительных органов государственной власти субъектов Российской Федерации» (СЗ РФ. 2000. № 25. Ст. 2728).

vi B соответствии с абзацем первым подп. 2.1 п. 2 постановления Конституционного Суда Российской Федерации от 07.06.2000 № 10 -П: «Суверенитет, предполагающий, по смыслу статей 3, 4, 5, 67 и 79 Конституции Российской Федерации, верховенство, независимость и самостоятельность государственной власти, полноту законодательной, исполнительной и судебной власти государства на его террито рии и независимость в международном общении, представляет собой необходимый качественный признак Российской Федерации как государства, характеризующий ее конституционно-правовой статус».

vii См.: Федеральный закон от 28.12.2010 № 390-Ф3 «О безопасности» (СЗ РФ. 2011. № 1. СТ. 2).

viii СМ., напр.: ст. 1 Закона СССР от 24.06.1991 № 2261-1 «О порядке вывоза, пересылки и истребования личных документов советских и иностранных граждан и лиц без гражданства из СССР за границу» (Ведомости СНД и ВС СССР. 1991. № 27. Ст. 784).

іх Федеральный закон от 31.05.1996 № 61-Ф3 «Об обороне» // СЗ РФ. 1996. № 23. СТ. 2750.

х Федеральный закон от 26.07.2017 № 187-ФЗ «О безопасности критической информационной инфраструктуры Российской Федерации» // СЗ РФ. 2017. № 31 (ч. І). СТ. 4736.

хі Федеральный закон от 27.05.1996 № 57-Ф3 «О государственной охране» // СЗ РФ. 1996. № 22. СТ. 2594.

хіі Федеральный закон от 21.07.2011 № 256-Ф3 «О безопасности объектов топливно-энергетического комплекса» // С3 РФ. 2011. № 30 (ч. 1). СТ. 4604.

хіiі Федеральный закон от 21.07.1997 № 117-ФЗ «О безопасности гидротехнических сооружений» // СЗ РФ. 1997. № 30. СТ. 3589.

хіv Федеральный закон от 10.12.1995 № 196-Ф3 «О безопасности дорожного движения» // СЗ РФ. 1995. № 50. СТ. 4873.

xv Обеспечение экономической безопасности - реализация органами государственной власти, органами местного самоуправления и Центрального банка Российской Федерации во взаимодействии с институтами гражданского общества комплекса политических, организационных, социально-экономических, информационных, правовых и иных мер, направленных на противодействие вызовам и угрозам экономической безопасности и защиту национальных интересов Российской Федерации в экономической сфере (подп. 7 п. 7 ст. І СЭБ РФ).

хvі См.: ст. 2 Федерального закона от 10.07.2002 № 86-Ф3 «О Центральном банке Российской Федерации (Банке России)» (С3 РФ. 2002. № 28. Ст. 2790).

хvіi См.: Федеральный закон от 30.12.2006 № 281-Ф3 «О специальных экономических мерах и принудительных мерах» (С3 РФ. 2007. № 1 (14.). СТ. 44).

xviii См.: программа «Цифровая экономика Российской Федерации», утв. распоряжением Правительства Российской Федерации от 28.07.2017 № 1632-р (СЗ РФ. 2017. № 32. СТ. 5138) - документ утратил силу с 12 февраля 2019 г. в связи с изданием распоряжения Правительства Российской Федерации от 12.02.2019 № 195-р (СЗ РФ. 2019. № 8. Ст. 803). 